\title{
Hypotonic contrast media is more toxic than isotonic contrast media on endothelial cells in vivo and in vitro
}

\author{
LIHUI REN ${ }^{1,2}$, PING WANG ${ }^{1}$, ZUOYAN WANG $^{1}$, YONG LIU $^{3 *}$ and SHUZHENG LV ${ }^{2 *}$ \\ ${ }^{1}$ Department of Cardiology, Beijing Shijitan Hospital, Beijing 100038; ${ }^{2}$ Department of Cardiology, Beijing Anzhen Hospital, \\ Capital Medical University, Beijing 100029; ${ }^{3}$ Department of Ultrasound, Beijing Shijitan Hospital, \\ Capital Medical University, Beijing 100038, P.R. China
}

Received July 25, 2016; Accepted May 11, 2017

DOI: $10.3892 / \mathrm{mmr} .2017 .7066$

\begin{abstract}
The aim of the current study was to investigate the cytotoxic effects of hypotonic (iopamidol) and isotonic (iodixanol) contract media (CMs) in vitro and in vivo. A total of 60 Wistar rats were included and were randomly divided into three groups (20 rats per group). Iodixanol (4 g iodine $/ \mathrm{kg}$ ), iopamidol (4 $\mathrm{g}$ iodine $/ \mathrm{kg}$ ) or equal volume of normal saline was injected via tail vein. HUVEC and H5V cell viability was determined by Cell Counting Kit- 8 agents. Western blotting was performed to detect ATP-binding cassette subfamily G member 1 (ABCG1) expression. For histological analysis, hematoxylin and eosin staining was performed. Plasma endothelin, von Willebrand factor, tissue type plasminogen activator, plasminogen activator inhibitor, D-Dimer, fibrinogen, anti-thrombin III, plasminogen and nitric oxide synthase (NOS) were measured by using ELISA. Both iopamidol and iodixanol treatments deceased cell viability and increased apoptosis of HUVEC and H5V cells, along with downregulated NOS and ABCG1. The injection of iopamidol or iodixanol into rats changed the endothelium-related plasma levels of biomarkers, including endothelin, von Willebrand factor, tissue type plasminogen activator, plasminogen activator inhibitor, D-Dimer, fibrinogen and anti-thrombin III. However, endothelia isolated from rat abdominal aorta in the iodixanol group retained their normal structure, whereas endothelial structure in the iopamidol group was injured and disrupted. The findings in
\end{abstract}

Correspondence to: Professor Shuzheng Lv, Department of Cardiology, Beijing Anzhen Hospital, Capital Medical University, 2 Anzhen Road, Beijing 100029, P.R. China

E-mail: drshuzheng@163.com

Dr Yong Liu, Department of Ultrasound, Beijing Shijitan Hospital, Capital Medical University, 10 Tieyi Road, Beijing 100038, P.R. China

E-mail: liuyongwz@126.com

*Contributed equally

Key words: contrast media, hypotonic, isotonic, endothelium, iopamidol, iodixanol the present study suggested that both hypotonic and isotonic CMs may lead to endothelial dysfunction and thrombin and fibrinolytic system disorder. However, hypotonic CMs may be more toxic than isotonic CMs. Therefore, additional cautions should be taken when selecting hypotonic CMs and their dosages during cardioangiography.

\section{Introduction}

Iodinated contrast medium (CM) is widely used in percutaneous cardiac interventions. The use of CMs in cardiac interventions may lead to a type of kidney dysfunction called contrast-induced nephropathy (CIN). As the number of interventional cardiac procedures is steadily increasing, CIN is now associated with the third highest number of hospital acquired nephropathy diagnoses (1-3). Though the mechanism underlying CIN has not been fully elucidated, it is believed that CIN is caused by a reduction in medullary blood flow (4) and direct tubular damage due to toxicity of CMs. Endothelial cells serve crucial roles in both mechanisms of CIN (5). Endothelial cells regulate renal hemodynamics by secreting numerous vasoactive substances to mediate vasoconstriction and vasodilation (6). Endothelin (ET) is one such vasoactive substance and may be upregulated during endothelial injury (7). The increase in ET levels results in vasoconstriction and may aggravate ischemia of the kidney. Nitric oxide (NO) is a key vasoactive substance that promotes vasodilation via nitric oxide synthase (NOS) $(8,9)$. Plasma NO is mainly synthesized by endothelial (e)NOS in endothelial cells (10). ATP-binding cassette subfamily G member 1 (ABCG1) is a crucial protein for maintaining normal endothelial cell functions (11). Deficiency of ABCG1 leads to apoptosis of endothelial cells (12). CMs can directly damage renal vascular endothelial cells and glomerulus renal tubule, eventually resulting in apoptosis $(13,14)$. In addition, dysfunction of endothelial cells may cause disorders of thrombin and the fibrinolytic system, resulting in thrombus formation (15).

CM-induced nephrotoxicity is closely related with the permeability, viscosity, ionization degree and dosage of selected CMs $(16,17)$. Currently, the development of iso-osmolar CMs is considered as a positive development to reduce the toxicity of CMs. However, the downside is that iso-osmolar CMs tend to be more viscous and may increase 
the toxicity and neutralize the benefits gained from low permeability. Therefore, in order to properly evaluate the safety of various CMs, it is critical to compare their toxicity, especially their cytotoxicity to endothelial cells. In the present study, the cytotoxic effects of hypotonic (iopamidol) and isotonic (iodixanol) CMs on endothelial cells were evaluated both in vitro and in vivo.

\section{Materials and methods}

Animals. A total of 60 Wistar rats were included in the current study. The rats were randomly divided into three groups (20 rats/group) and injected with iodixanol (4 g iodine $/ \mathrm{kg}$ body weight), iopamidol ( $4 \mathrm{~g}$ iodine/ $\mathrm{kg}$ body weight) or an equal volume of normal saline via tail vein. The rats were then randomly divided into 4 subgroups according to the time points following injection and were sacrificed at $0.5,2,12$ or $24 \mathrm{~h}$ following injection, respectively. Blood samples, collected from the abdominal aorta for each animal, were treated with heparin to prevent coagulation and centrifuged at $670.8 \mathrm{x}$ g for $10 \mathrm{~min}$ at $4^{\circ} \mathrm{C}$. Plasma samples were then immediately transferred to $-80^{\circ} \mathrm{C}$ for future tests. All animal experiments were conducted according to the ethical guidelines.

Cells. HUVEC cells were cultured in F12K medium containing $10 \%$ fetal bovine serum (FBS), $0.1 \mathrm{mg} / \mathrm{ml}$ heparin and $0.03-0.05 \mathrm{mg} / \mathrm{ml}$ endothelial cell growth supplement. H5V cells (mouse endothelial cells) were cultured in Dulbecco's modified Eagle's medium containing 10\% FBS. All of these cells were maintained in an atmosphere of $5 \% \mathrm{CO}_{2}$ at $37^{\circ} \mathrm{C}$.

Cell Counting Kit (CCK)-8 assay. Cells were seeded into 96 -well plates $\left(5 \times 10^{4} /\right.$ well) and cultured for $24 \mathrm{~h}$ before use. Cells were then treated with $10 \mathrm{mg}$ iodine $/ \mathrm{ml}$ iodixanol or iopamidol for $30 \mathrm{~min}, 2,12$ or $24 \mathrm{~h}$, respectively. Cell viability was determined by using CCK-8 agents following the manufacturer's manual (Dojindo Molecular Technologies, Inc., Kumamoto, Japan).

Western blotting. Cells were lysed with a protein extraction buffer [50 mM Tris (pH 7.4), $150 \mathrm{mM} \mathrm{NaCl}, 1 \% \mathrm{NP}-40$ and $0.5 \%$ sodium deoxycholate], then quantified using a bicinchoninic acid kit (cat no. orb219872; Wuhan Booute Biotechnology Co., Ltd., Wuhan, China) according to the manufacturer's instructions. Proteins (100 $\mu \mathrm{g} /$ well) were then loaded onto $10 \%$ SDS-PAGE gels for electrophoresis. Protein was blotted onto nitrocellulose membrane and blocked with 5\% skimmed milk at room temperature for $2 \mathrm{~h}$. Then, the membrane was incubated at $4^{\circ} \mathrm{C}$ for $2 \mathrm{~h}$ with antibodies against ABCG1 (cat no. PL0402507; 1:1,000; Santa Cruz Biotechnology, Inc., Dallas, TX, USA) and GAPDH (cat no. A01020; 1:10,000; Abbkine Scientific Co., Ltd., Wuhan, China). Following washing with TBS containing 0.1\% Tween-20 for 4 times, the membrane was incubated with a horseradish peroxidase-conjugated secondary antibody (cat no. B1254; 1:1,000; Beijing Yonghui Biological Technology Co., Ltd., Beijing, China) at $4^{\circ} \mathrm{C}$ for $2 \mathrm{~h}$. Specific bands were measured by using SuperSignal West Femto Maximum Sensitivity substrate (Pierce; Thermo Fisher Scientific Inc., Waltham, MA, USA). The specific band intensities were quantified with
Quantity One software (version, 4.6.2; Bio-Rad Laboratories, Inc., Hercules, CA, USA).

Hematoxylin and eosin staining. Abdominal aortae from each subgroup were washed with PBS and fixed in $4 \%$ paraformaldehyde, dehydrated and embedded in paraffin and cut into $4 \mu \mathrm{m}$ thick sections. The sections were de-paraffinized with xylene and subsequently rehydrated. For routine histological analysis, the sections were stained with hematoxylin and eosin. For immunohistochemistry staining, the sections were treated with $3 \% \mathrm{H}_{2} \mathrm{O}_{2}$ in PBS for 30 min to block the endogenous peroxidase and heat-repaired in $0.01 \mathrm{M}$ citrate buffer for $15 \mathrm{~min}$. The sections were further blocked by normal goat serum for $30 \mathrm{~min}$ at room temperature prior to primary anti-endothelial nitric oxide synthase antibody (cat no. 4231; 1:1,000; Cell Signaling Technology, Inc., Danvers, MA, USA) incubation at $4^{\circ} \mathrm{C}$ overnight. On the next day, the sections were incubated with biotin-conjugated goat anti-rabbit secondary antibody (cat no. sc-2007; 1:1,000; Santa Cruz Biotechnology, Inc.) for $2 \mathrm{~h}$ at $37^{\circ} \mathrm{C}$ followed by incubation in $\mathrm{S}-\mathrm{A} /$ horseradish peroxidase (Santa Cruz Biotechnology, Inc.) for $15 \mathrm{~min}$ at room temperature. Following this, the sections were counterstained with hematoxylin, dehydrated, mounted with neutral gum and observed using Olympus IX71 microscope (Olympus Corporation, Tokyo, Japan).

ELISA. Plasma ET, von Willebrand factor (vWF), tissue type plasminogen activator (t-PA), plasminogen activator inhibitor (PAI), D-Dimer, fibrinogen (FG), anti-thrombin III (AT-III), plasminogen (PLG) and NOS from cell culture medium were measured by using ELISA kits [Beijing Yonghui Biological Technology Co, Ltd.; Plasma ET (cat no. GD-VN9950), vWF, t-PA, PAI, D-Dimer and FG (cat no. QY-VN3291), AT-III (cat no. E04298), PLG (cat no. E00403) and NOS (cat no. JK-(a)-1609)]. Briefly, samples were applied to a 96-well plate $\left(1 \times 10^{5} /\right.$ well $)$ with pre-coated capture antibodies for $2 \mathrm{~h}$ at $37^{\circ} \mathrm{C}$. Then, the plates were washed and incubated with biotinylated antibodies (cat no. 500-P39Bt; 1:1,000; PeproTech, Inc., Rocky Hill, NJ, USA) at $37^{\circ} \mathrm{C}$ for $2 \mathrm{~h}$. The plates were then washed five times and incubated with streptavidin-horseradish peroxidase (Beijing Yonghui Biological Technology Co, Ltd.; cat. no. $554066 ; 1: 1,000)$ at $37^{\circ} \mathrm{C}$ for $30 \mathrm{~min}$. The plates were washed again for five times and horseradish peroxidase substrates were added. The reactions were stopped after $30 \mathrm{~min}$. Optical density was measured at $450 \mathrm{~nm}$ by using a microplate reader (Thermo Fisher Scientific, Inc.).

Statistical analysis. All values were presented as means \pm standard deviation. Two-tailed Student's t-test was performed using SPSS 17.0 software (SPSS Inc., Chicago, IL, USA) to determine the statistical significance of the results between two groups. $\mathrm{P}<0.05$ was considered to indicate a statistically significant difference.

\section{Results}

Damages of endothelial cells treated with iodixanol were less severe than those treated with iopamidol in vitro. To examine the effect of CMs on endothelial cells in vitro, HUVEC and H5V cells were treated with $10 \mathrm{mg}$ iodine $/ \mathrm{ml}$ 

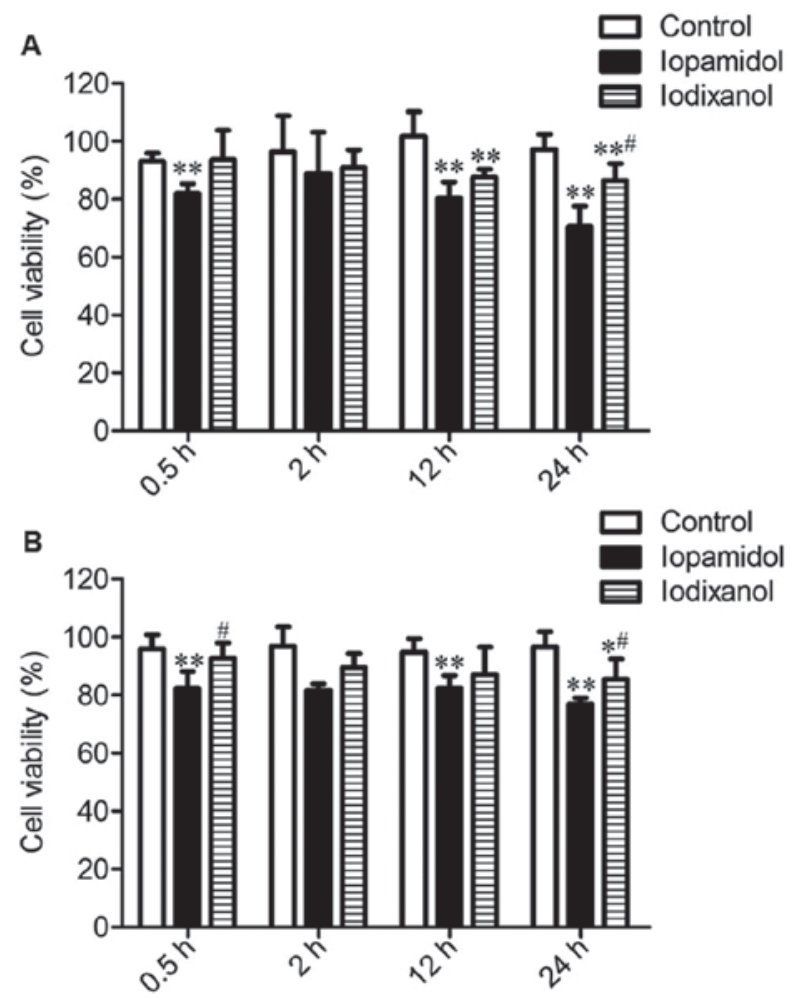

C
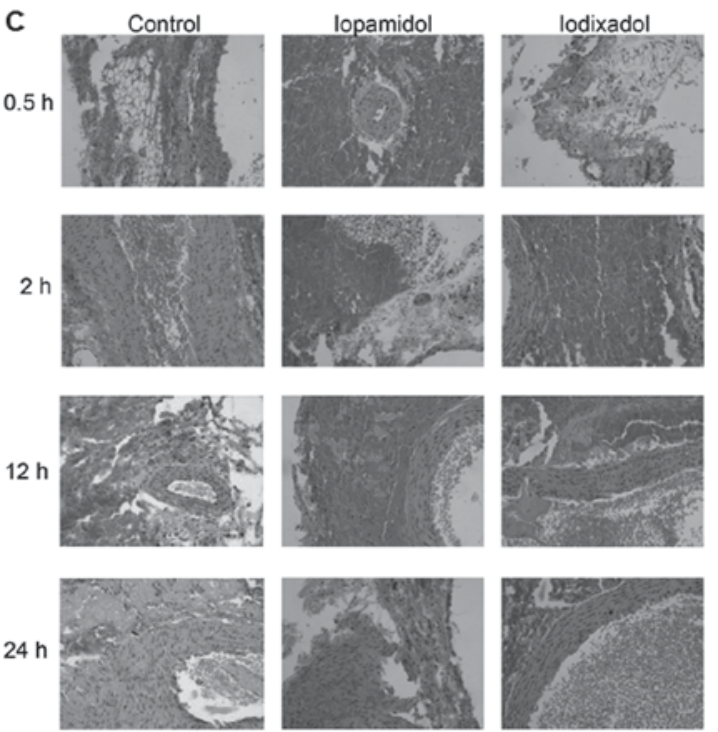

Figure 1. Effect of contrast media on endothelia in vitro and in vivo. (A) HUVEC and (B) H5V cell viability following treatment with $10 \mathrm{mg}$ iodine $/ \mathrm{ml}$ iopamidol or iodixanol for the indicated time. Cell Counting Kit- 8 assays were performed to measure cell viability. The data were obtained from three independent experiments and are expressed as means \pm standard deviation. (C) Endothelial structures in abdominal aorta of Wistar rats injected with $4 \mathrm{~g}$ iodine $/ \mathrm{kg}$ iopamidol, iodixanol or equal volume of normal saline (as control) for the indicated time. Sections from abdominal aorta in each group were observed by using microscope. Magnification, x100. Representative graphs are shown $(\mathrm{n}=5)$. ${ }^{*} \mathrm{P}<0.05,{ }^{* *} \mathrm{P}<0.01$ vs. control group; ${ }^{\#} \mathrm{P}<0.05$ vs. iopamidol group.

iodixanol or iopamidol for $0.5,2,12$ or $24 \mathrm{~h}$, and cell viability in each group was evaluated by CCK-8 assay. Iopamidol and iodixanol treatments reduced cell viability at 12 and $24 \mathrm{~h}$ in both HUVEC and H5V cells, but iopamidol group had lower cell viability than that in iodixanol group (Fig. 1A and B). These results indicated that damages of endothelial cells

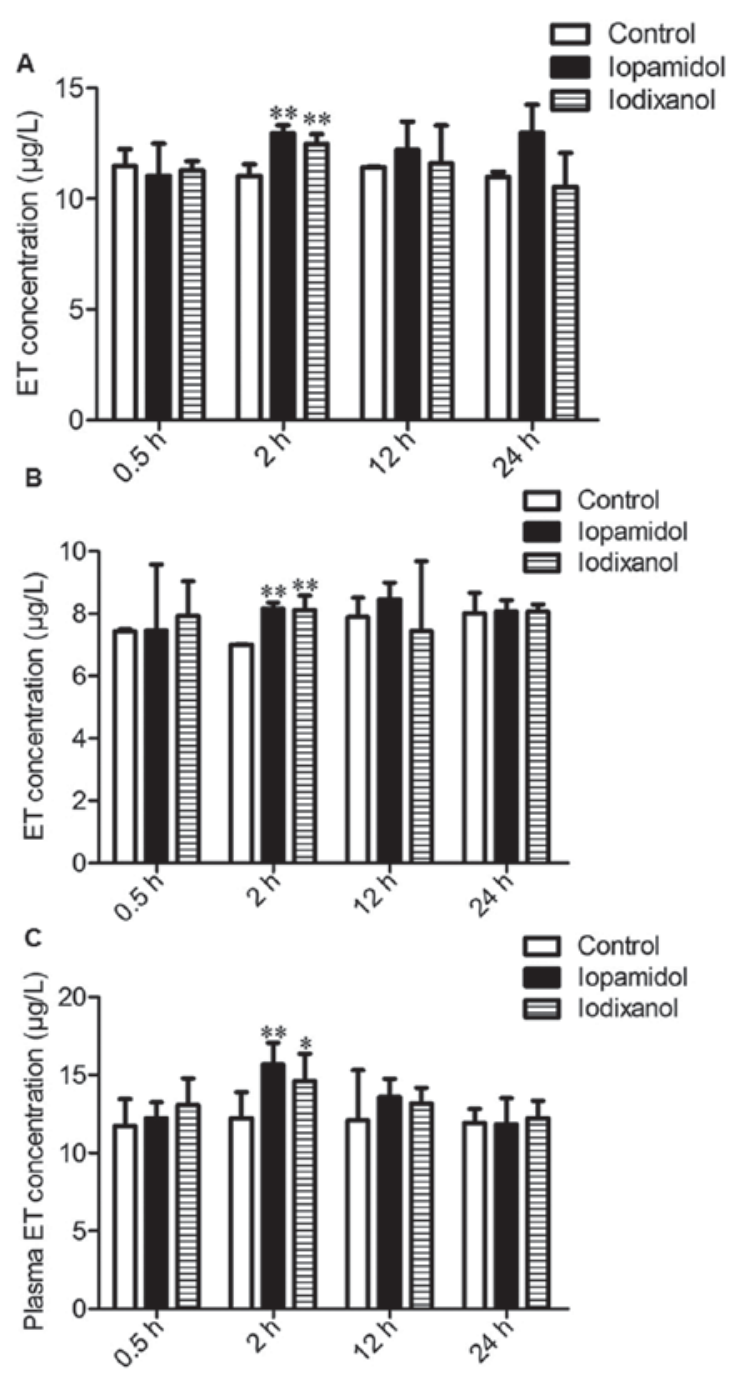

Figure 2. Effect of contrast media on endothelin in (A) HUVEC cells, (B) H5V cells and (C) rat plasma. The cells were incubated with $10 \mathrm{mg}$ iodine $/ \mathrm{ml}$ iopamidol or iodixanol for the indicated time, and ELISA assays were performed to measure endothelin levels. Wistar rats were injected with $4 \mathrm{~g}$ iodine/ $\mathrm{kg}$ iopamidol, iodixanol or equal volume of normal saline (as control) for the indicated time, and plasma ET was detected by using ELISA assay $(n=5)$. All data were obtained from at least three independent experiments and are expressed as means \pm standard deviation. ${ }^{*} \mathrm{P}<0.05,{ }^{* *} \mathrm{P}<0.01$ vs. control group. ET, endothelin.

treated with iodixanol were less severe than those treated with iopamidol.

Isotonic CM was less toxic than hypotonic CM to endothelial cells in vivo. To further investigate whether CMs induce endothelial cell injury in vivo, iopamidol, iodixanol or equal volume of normal saline were injected into three groups of rats via tail vein, respectively, and abdominal aorta was dissected and the endothelial structure from dissected tissue was examined at $0.5,2,12$ and $24 \mathrm{~h}$ following injections. The endothelial structure was smooth and intact in both control group and iodixanol group (Fig. 1C). In the iopamidol group, endothelial structure was normal at $0.5,2$ and $12 \mathrm{~h}$ following injection, but endothelia were injured and their integrity was disrupted at $24 \mathrm{~h}$ following injection (Fig. 1C). These findings indicated that isotonic CM was less toxic than hypotonic CM to endothelial cells in vivo. 

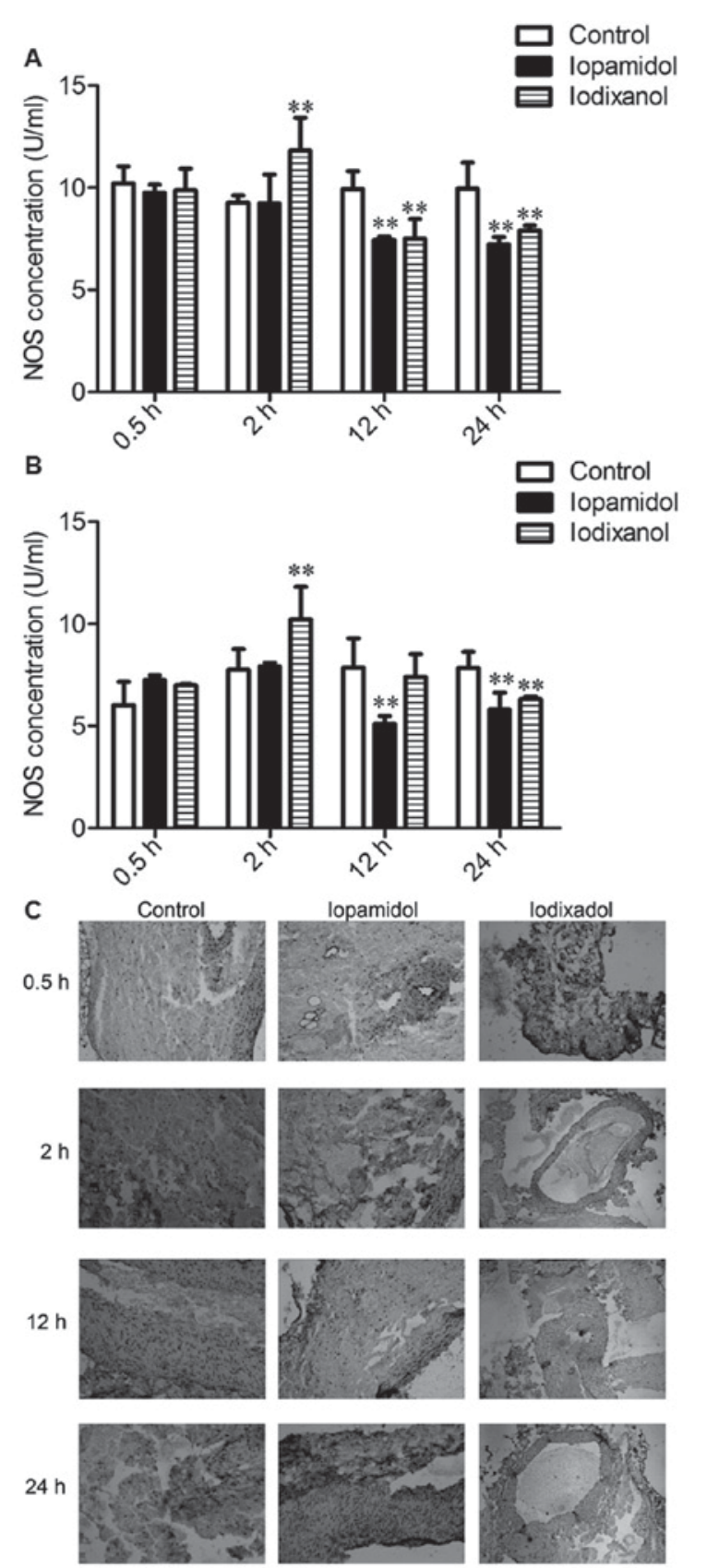

Figure 3. Effect of contrast media on NOS in (A) HUVEC cells, (B) H5V cells, and (C) rat plasma (magnification, $\mathrm{x} 100$ ). The cells were incubated with $10 \mathrm{mg}$ iodine/ml iopamidol or iodixanol for the indicated time, and ELISA assays were performed to detect the expression of NOS. Wistar rats were injected with $4 \mathrm{~g}$ iodine $/ \mathrm{kg}$ iopamidol, iodixanol or equal volume of normal saline (as control) for the indicated time. eNOS in endothelia of abdomina aorta was detected by immunohistochemistry. Representative graphs are shown. All data were obtained from at least three independent experiments and are expressed as means \pm standard deviation. ${ }^{* *} \mathrm{P}<0.01$ vs. control group. NOS, nitric oxide synthase; eNOS, endothelium-derived NOS

CMs cause dysfunction of endothelial cells, which may be involved in CM-mediated cytotoxicity. To measure the levels of ET, NOS and ABCG1 in CM-treated cells in vitro, ELISA was employed. It was demonstrated that both iopamidol and iodixanol significantly increased the secretion of ET in HUVEC and H5V cells without significant differences between iopamidol and iodixanol (Fig. 2A and B). In addition, both iopamidol and iodixanol increased plasma ET levels at
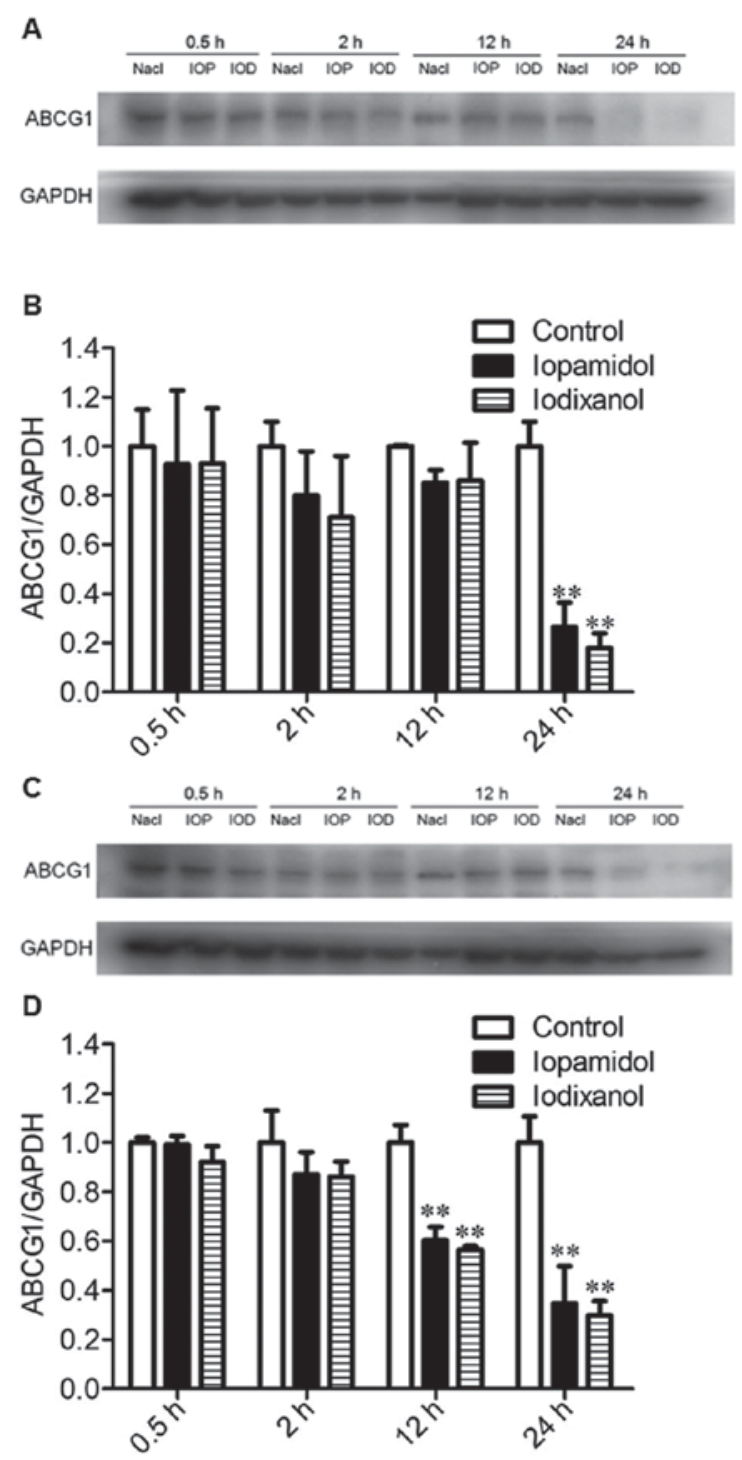

Figure 4. Effect of contrast media on the expression of ABCG1 in (A and B) HUVEC cells and (C and D) H5V cells. The cells were incubated with $10 \mathrm{mg}$ iodine/ml IOP or IOD for the indicated time, and western blotting was performed to detect the expression of ABCG1 in the cells. (B and D) Data were obtained from three independent experiments and are expressed as means \pm standard deviation. (A and C) The band intensity was normalized to GAPDH. ${ }^{* *} \mathrm{P}<0.01$ vs. control group. ABCG1, ATP-binding cassette subfamily G member 1; IOD, iodixanol; IOP, iopamidol.

$2 \mathrm{~h}$ following injection and no significant difference in plasma ET levels was observed between iopamidol and iodixanol groups (Fig. 2C). In both HUVEC cells and H5V cells, iodixanol dramatically increased NOS levels at $2 \mathrm{~h}$, whereas iopamidol did not. NOS levels were then significantly reduced at 12 and $24 \mathrm{~h}$ in HUVEC and H5V cells after treatment with iopamidol or ioxianol (Fig. 3A and B). Similar results were identified in dissected abdominal aorta tissue samples by endothelium-derived (e)NOS immunohistochemistry staining. The data demonstrated that eNOS was upregulated in both iopamidol and iodixanol groups at $2 \mathrm{~h}$ following injection, but downregulated at 12 and $24 \mathrm{~h}$ after injection compared with the control group (Fig. 3C). Furthermore, both iopamidol and iodixanol inhibited the expression of ABCG1 in HUVEC or H5V cells (Fig. 4). These results together indicated that CMs 

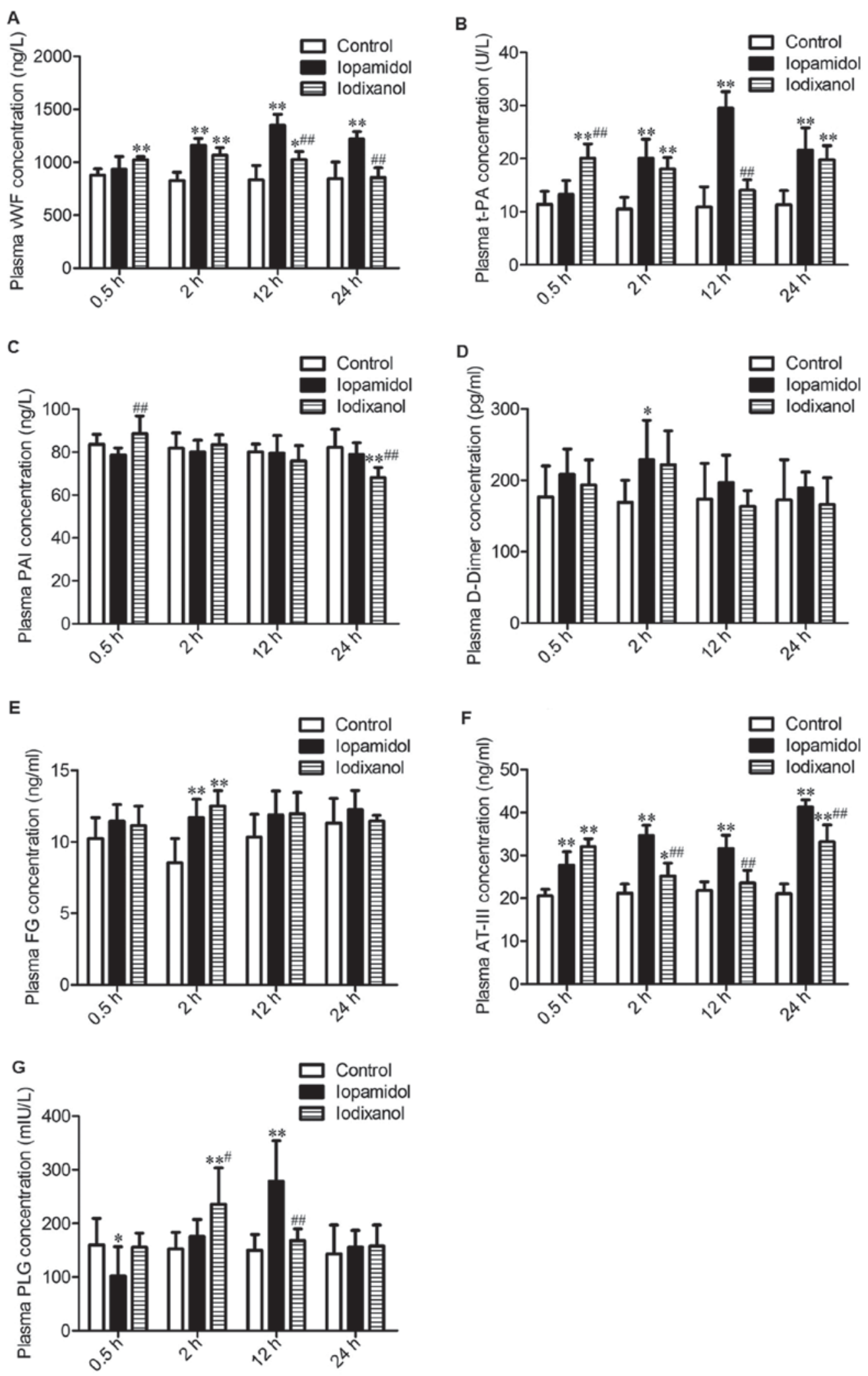

Figure 5. Effect of contrast media on the levels of plasma thrombin and fibrinolytic biomarkers. (A-G) Wistar rats were injected with $4 \mathrm{~g}$ iodine/kg iopamidol, iodixanol or equal volume of normal saline (as control) for the indicated time. (A) Plasma von Willebrand factor, (B) t-PA, (C) PAI, (D) D-Dimer, (E) FG, (F) AT-III and (G) PLG were measured by using ELISA assays. Data were obtained from at least three independent experiments and are expressed as means \pm standard deviation. ${ }^{*} \mathrm{P}<0.05,{ }^{* *} \mathrm{P}<0.01$ vs. control group; ${ }^{~} \mathrm{P}<0.05$ vs. iopamidol group. vWF, von Willebrand factor; t-PA, tissue type plasminogen activator; PAI, plasminogen activator inhibitor; FG, fibrinogen; AT-III, anti-thrombin III; PLG, plasminogen.

cause dysfunction of endothelial cells, which may be involved in CM-mediated cytotoxicity.
Dysfunction of endothelial cells induced by CMs may be involved in thrombin and fibrinolytic system disorder and 
hence, increasing the risk of thrombus formation. To compare whether iopamidol and iodixanol have similar effects on thrombin and fibrinolytic system, plasma levels of vWF, t-PA, PAI-1, D-Dimer, FG, AT-III and PLG were measured using ELISA. The data indicated that plasma vWF level was upregulated following iopamidol and iodixanol treatments at 0.5, 2 and $12 \mathrm{~h}$ after injection. However, plasma vWF returned to a normal level at $24 \mathrm{~h}$ in iodixanol group, but remained high in iopamidol group (Fig. 5A). Plasma t-PA concentration was also significantly increased in rats injected with iopamidol and iodixanol compared to control (Fig. 5B). Compared with the iodixanol group, the iopamidol group showed a lower concentration of plasma t-PA at $0.5 \mathrm{~h}$ following injection, but dramatically higher concentration of plasma t-PA at 12 h (Fig. 5B). Plasma PAI-1 levels in iopamidol group were comparable to that of the control, but iodixanol significantly downregulated the expression of PAI-1 at $24 \mathrm{~h}$ following injection (Fig. 5C). In addition, iopamidol increased plasma D-Dimer at $2 \mathrm{~h}$ after injection, while iodixanol did not significantly alter plasma D-Dimer concentration (Fig. 5D). Both iopamidol and iodixanol increased plasma $\mathrm{FG}$ at $2 \mathrm{~h}$ after injection compared with the control, but no significant difference was observed between iopamidol and iodixanol (Fig. 5E). Both iopamidol and iodixanol only increased plasma FG levels at $2 \mathrm{~h}$ after injection and did not significantly impact plasma FG levels at 0.5, 12 and $24 \mathrm{~h}$ following injection compared with control (Fig. 5E). Plasma AT-III levels were elevated at 2, 12 and $24 \mathrm{~h}$ after injection, but iopamidol group showed higher levels of AT-III than the iodixanol group (Fig. 5F). Plasma PLG levels were increased in both iopamidol and iodixanol groups, but the peak concentration of plasma PLG in the iopamidol group was at $12 \mathrm{~h}$ after injection, which was later than the iodixanol group ( $2 \mathrm{~h}$ after injection) (Fig. 5G). These results suggested that dysfunction of endothelial cells induced by $\mathrm{CMs}$ may be involved in thrombin and fibrinolytic system disorder and hence, increasing the risk of thrombus formation.

\section{Discussion}

In the present study, the toxicity of two commonly used CMs on endothelial cells was investigated in vitro and in vivo. The results demonstrated that both of iopamidol and iodixanol could significantly induce cellular damage to endothelial cells, and iopamidol was more toxic than iodixanol on endothelial cells. Although the mechanism of CIN remains unclear, perturbation of renal haemodynamics induced by CM may be involved (18). Some earlier studies indicate that the toxicity of CMs may be associated with their permeability (17). However, other researchers claim that permeability of CMs is not the primary cause of CIN. It is believed that CIN is caused by the combination of a reduction in medullary blood flow and direct tubular damage due to toxicity of CMs (19). Our results suggested that both iopamidol and iodixanol are able to cause endothelial cell injury in vitro and in vivo despite of their different permeability. Furthermore, the data support the fact that the toxicity of iodaxinol on endothelial cells is lower than iopamidol. It is indicated that permeability may be associated with CM-induced endothelial cell injury, but does not serve a critical role. On the other hand, these data suggested that isotonic CMs may be safer than hypotonic CMs.
Endothelial cells synthesize and secrete numerous vasoactive substances (20). NO and ET are two primary substances oppositely functioned to each other regarding vasoconstriction and vasodilation (21). Therefore, NO and ET are used as biomarkers to reflect the function of endothelial cells (22). In CIN models, the expression of ET is downregulated, leading to vasoconstriction (23). The results demonstrated that both iopamidol and iodixanol upregulate ET levels, indicating that the two CMs are able to induce injury in endothelial cells. NO is synthesized by eNOS in endothelial cells, and the expression of eNOS is downregulated during endothelial cell injury (24). Our research shows that both iopamidol and iodixanol downregulate eNOS expression, indicating that the two CMs result in endothelial cell dysfunction. Because reduced expression of vasodilators and overexpression of vasoconstrictors could induce ischemia of the kidney, they may be novel therapeutic targets for CIN.

ABCG1 is a member of ABC transporter that is broadly expressed in various tissues $(25,26)$. In endothelial cells, ABCG1 mediates cholesterol exporting, which protects the normal function of endothelial cells (27-29). The current study finds that both iopamidol and iodixanol downregulate ABCG1 expression, suggesting that CMs with different permeability could disrupt normal function of endothelial cells. The data further support that the permeability of CMs may be associated with CM-induced endothelial dysfunction.

Dysfunction of endothelial cells may cause thrombin and fibrinolytic system disorder. A previous study reported that CMs upregulate plasma vWF level (30). Consistently, a significant increase of vWF was observed following iopamidol or iodixanol treatment. Our data also indicated that iopamidol treatment results in a more dramatic increase of vWF compared with iodixanol.Likewise, other thrombin and fibrinolytic biomarkers are also affected by iopamidol or iodixanol. Interestingly, the study also demonstrated that some plasma biomarkers fluctuate at different time points after treatments. This phenomenon indicates that CM-mediated thrombin and fibrinolytic system disorder may be complex and time-dependent, but the injury of endothelial cells may be involved in the process. The disorder of thrombin and fibrinolytic system induced by CM may cause high risk of thrombus formation, and may increase ischemia of the kidney. Therefore, pharmacologically interfering with the thrombin and fibrinolytic system may be another therapeutic target for the treatment of CIN. Although several novel hypotonic or isotonic CMs have been developed for clinical use, the cytotoxicity of CMs on endothelial cells appears to be inevitable $(31,32)$. Therefore, cautiously choosing the types of CMs and properly calculating the doses can reduce the risk of CIN.

\section{Acknowledgements}

The present study was supported by the Capital Health Research and Development Special Foundation of China (grant no. 2014-4-2082), and Basic Clinical Research Cooperation Project of Capital Medical University (grant no. 14JL87).

\section{References}

1. Azzalini L, Spagnoli V and Ly HQ: Contrast-induced nephropathy: From pathophysiology to preventive strategies. Can J Cardiol 32: 247-255, 2016. 
2. Blann AD, Adams R, Ashleigh R, Naser S, Kirkpatrick U and McCollum CN: Changes in endothelial, leucocyte and platelet markers following contrast medium injection during angiography in patients with peripheral artery disease. Br J Radiol 74 811-817, 2001.

3. Burgess WP and Walker PJ: Mechanisms of contrast-induced nephropathy reduction for saline $(\mathrm{NaCl})$ and sodium bicarbonate (NaHCO3). Biomed Res Int 2014: 510385, 2014.

4. Caiazza A, Russo L, Sabbatini M and Russo D: Hemodynamic and tubular changes induced by contrast media. Biomed Res Int 2014: 578974, 2014.

5. Chang CF and Lin CC: Current concepts of contrast-induced nephropathy: A brief review. J Chin Med Assoc 76: 673-681, 2013.

6. Deanfield JE, Halcox JP and Rabelink TJ: Endothelial function and dysfunction: Testing and clinical relevance. Circulation 115 1285-1295, 2007

7. Fens MH, Larkin SK, Oronsky B, Scicinski J, Morris CR and Kuypers FA: The capacity of red blood cells to reduce nitrite determines nitric oxide generation under hypoxic conditions PLoS One 9: e101626, 2014.

8. Förstermann U and Sessa WC: Nitric oxide synthases: Regulation and function. Eur Heart J 33: 829-837, 2012.

9. Gross SS, Stuehr DJ, Aisaka K, Jaffe EA, Levi R and Griffith OW: Macrophage and endothelial cell nitric oxide synthesis: Cell-type selective inhibition by NG-aminoarginine, NG-nitroarginine and NG-methylarginine. Biochem Biophys Res Commun 170 96-103, 1990

10. Haller $\mathrm{C}$ and Hizoh I: The cytotoxicity of iodinated radiocontrast agents on renal cells in vitro. Invest Radiol 39: 149-154, 2004.

11. Higashi Y: Assessment of endothelial function. History, methodological aspects, and clinical perspectives. Int Heart J 56: 125-134, 2015.

12. Hsu SP, Tsai TJ and Chien CT: Ioxitalamate induces renal tubular apoptosis via activation of renal efferent nerve-mediated adrenergic signaling, renin activity, and reactive oxygen species production in rats. Toxicol Sci 114: 149-158, 2010.

13. Katsiki N, Athyros VG, Karagiannis A and Mikhailidis DP Contrast-induced nephropathy: An 'All or None' phenomenon? Angiology 66: 508-513, 2015

14. Kennedy MA, Barrera GC, Nakamura K, Baldán A, Tarr P, Fishbein MC, Frank J, Francone OL and Edwards PA: ABCG1 has a critical role in mediating cholesterol efflux to HDL and preventing cellular lipid accumulation. Cell Metab 1: 121-131, 2005.

15. Machovich R: Blood coagulation-fibrinolytic system and endothelial cells. Acta Biochim Biophys Acad Sci Hung 20: 135-153, 1985.

16. Münch G, Bültmann A, Li Z, Holthoff HP, Ullrich J, Wagner S and Ungerer M: Overexpression of ABCG1 protein attenuates arteriosclerosis and endothelial dysfunction in atherosclerotic rabbits. Heart Int 7: e12, 2012.

17. Nazıroğlu M, Yoldas N, Uzgur EN and Kayan M: Role of contrast media on oxidative stress, $\mathrm{Ca}(2+)$ signaling and apoptosis in kidney. J Membr Biol 246: 91-100, 2013.

18. Ni L, Li T, Liu B, Song X, Yang G, Wang L, Miao S and Liu C: The protective effect of Bcl-xl overexpression against oxidative stress-induced vascular endothelial cell injury and the role of the Akt/eNOS pathway. Int J Mol Sci 14: 22149-22162, 2013.
19. Nicola R, Shaqdan KW, Aran K, Mansouri M, Singh A and Abujudeh HH: Contrast-induced nephropathy: Identifying the risks, choosing the right agent, and reviewing effective prevention and management methods. Curr Probl Diagn Radiol 44 501-504, 2015.

20. O'Connell BJ, Denis M and Genest J: Cellular physiology of cholesterol efflux in vascular endothelial cells. Circulation 110: 2881-2888, 2004

21. Persson PB and Tepel M: Contrast medium-induced nephropathy: The pathophysiology. Kidney Int Suppl: S8-S10, 2006.

22. Peterson KM, Franchi F, Loeffler DL, Psaltis PJ, Harris PC, Lerman LO, Lerman A and Rodriguez-Porcel M: Endothelial dysfunction occurs prior to clinical evidence of polycystic kidney disease. Am J Nephrol 38: 233-240, 2013.

23. Rapoport RM: Nitric oxide inhibition of endothelin-1 release in the vasculature: In vivo relevance of in vitro findings. Hypertension 64: 908-914, 2014.

24. Rudnick MR, Goldfarb S, Wexler L, Ludbrook PA, Murphy MJ, Halpern EF, Hill JA, Winniford M, Cohen MB and VanFossen DB: Nephrotoxicity of ionic and nonionic contrast media in 1196 patients: A randomized trial. The iohexol cooperative study. Kidney Int 47: 254-261, 1995.

25. Scoditti E, Massaro M and Montinari MR: Endothelial safety of radiological contrast media: Why being concerned. Vascul Pharmacol 58: 48-53, 2013.

26. Terasaka N, Yu S, Yvan-Charvet L, Wang N, Mzhavia N, Langlois R, Pagler T, Li R, Welch CL, Goldberg IJ and Tall AR: ABCG1 and HDL protect against endothelial dysfunction in mice fed a high-cholesterol diet. J Clin Invest 118: 3701-3713, 2008.

27. Whetzel AM, Sturek JM, Nagelin MH, Bolick DT, Gebre AK, Parks JS, Bruce AC, Skaflen MD and Hedrick CC: ABCG1 deficiency in mice promotes endothelial activation and monocyte-endothelial interactions. Arterioscler Thromb Vasc Biol 30: 809-817, 2010.

28. Wong PC, Li Z, Guo J and Zhang A: Pathophysiology of contrast-induced nephropathy. Int J Cardiol 158: 186-192, 2012.

29. Xue J, Wei J, Dong X, Zhu C, Li Y, Song A and Liu Z: ABCG1 deficiency promotes endothelial apoptosis by endoplasmic reticulum stress-dependent pathway. J Physiol Sci 63: 435-444, 2013

30. Xue JH, Yuan Z, Wu Y, Liu Y, Zhao Y, Zhang WP, Tian YL, Liu WM, Liu Y and Kishimoto C: High glucose promotes intracellular lipid accumulation in vascular smooth muscle cells by impairing cholesterol influx and efflux balance. Cardiovasc Res 86: 141-150, 2010

31. Zembowicz A, Hecker M, Macarthur H, Sessa WC and Vane JR: Nitric oxide and another potent vasodilator are formed from NG-hydroxy-L-arginine by cultured endothelial cells. Proc Natl Acad Sci USA 88: 11172-11176, 1991.

32. Zhao Y, Tao Z, Xu Z, Tao Z, Chen B, Wang L, Li C, Chen L, Jia Q, Jia E, et al: Toxic effects of a high dose of non-ionic iodinated contrast media on renal glomerular and aortic endothelial cells in aged rats in vivo. Toxicol Lett 202: 253-260, 2011. 